\title{
AVALIAÇÃO DAS CONDIÇÕES SOCIOECONÔMICAS E AMBIENTAIS DE PROPRIEDADES AGRÍCOLAS DO MUNICÍPIO DE ILHA SOLTEIRA - SÃO PAULO, BRASIL
}

\section{ASSESSMENT OF CONDITIONS SOCIOECONOMIC AND ENVIRONMENTAL AGRICULTURAL PROPERTIES IN ILHA SOLTEIRA - SÃO PAULO, BRAZIL}

\section{Mauro Martins ${ }^{1}$; Juliana Heloisa Pinê Américo² ; Sérgio Luís de Carvalho $^{3 *}$; Elizete Aparecida Checon de Freitas-Lima ${ }^{3}$}

\author{
${ }^{1}$ Coordenadoria de Defesa Agropecuária - Inspetoria de Defesa Agropecuária de \\ Pereira Barreto/SP \\ ${ }^{2}$ Centro de Aquicultura da Universidade Estadual Paulista "Júlio de Mesquita Filho" \\ UNESP (CAUNESP), Jaboticabal, SP. \\ ${ }^{3}$ Departamento de Biologia e Zootecnia, Faculdade de Engenharia de Ilha Solteira \\ (FEIS/UNESP)Universidade Estadual Paulista "Júlio de Mesquita Filho" \\ *Autor para correspondência. E-mail: sergicar@bio.feis.unesp.br
}

\begin{abstract}
RESUMO
O objetivo do trabalho foi avaliar as condições socioeconômicas e os problemas ambientais em propriedade rurais do município de Ilha Solteira, Estado de São Paulo e verificar como esses problemas são tratados de acordo com o grau de conscientização dos produtores. Foram visitadas 50 propriedades rurais, onde se aplicou um questionário envolvendo aspectos sociais, econômicos e os principais problemas de degradação ambiental. Abordaram-se aspectos relacionados ao uso e conservação do solo, disposição de resíduos sólidos e líquidos, descarte das embalagens de agrotóxicos, uso de equipamentos de proteção individual e lançamento de esgotos nas propriedades, entre outras ocorrências, procurando-se também avaliar a importância que os produtores e agregados atribuem aos recursos naturais e ao meio ambiente. Foram identificados diversos processos de degradação ambiental traduzidos por problemas de erosão, principalmente nas grandes propriedades, formas inadequadas de disposição dos resíduos sólidos, inadequação no descarte de embalagens de agrotóxicos falta do uso de equipamentos de proteção individual em algumas propriedades e pelo lançamento de grande parte dos esgotos em fossas negras.

Palavras-chave: Meio ambiente. Recursos naturais. Degradação ambiental. Educação ambiental.
\end{abstract}

\footnotetext{
ABSTRACT

The aims was to evaluate the socioeconomic conditions and environmental problems in rural property in the municipality Ilha Solteira, State of São Paulo and check how these problems are handled according to the degree of awareness of the producers. 50 farms were visited, which applied a questionnaire involving social, economic aspects and the main problems of environmental degradation. Addressed to aspects of the use and conservation of soil, disposal of solid and liquid
} 
waste, disposal of pesticide containers, use of personal protective equipment and dumping of sewage in the properties, among other events, also looking to evaluate the importance producers and aggregates attach to natural resources and the environment. Various environmental degradation processes translated by erosion problems were identified, especially in large properties, inadequate forms of disposal of solid waste, inadequate disposal of the packaging of pesticides lack of use of personal protective equipment in some properties and the release of most sewage in black tanks.

Keywords: Environment. Natural resources. Environmental degradation. Environmental education

\section{INTRODUÇÃO}

O município de Ilha Solteira - SP teve sua origem com a construção da Usina Hidrelétrica de Ilha Solteira, que estabeleceu seu núcleo urbano, em 1968, planejado para abrigar o grande contingente de pessoas empenhadas na construção da obra, e em 1991, conquistou sua emancipação político-administrativa. Atualmente esse município é um polo de desenvolvimento regional, com elevado índice de desenvolvimento humano (IDH), o décimo entre os municípios paulistas. O efeito antropogênico provocado pela instalação de uma sociedade urbanizada aliada a expansão das fronteiras agrícolas que ocorreu de maneira intensa, causou grande impacto ambiental sobre os sistemas naturais.

A degradação do solo e a baixa produtividade agrícola são fatores recorrentes no meio rural. Esses fatores estão associados ao esgotamento dos nutrientes do solo, processos erosivos e ao desmatamento que podem em longo prazo afetar a biodiversidade dos ecossistemas (PENDER et al., 2004). Assim, o produtor rural está utilizando cada vez mais fertilizantes, defensivos, corretivos de acidez de solo, máquinas agrícolas e energia elétrica visando obter com isso maior produtividade além de reduzir seus custos com empregados (MOURA, 2004).

A construção da Usina Hidrelétrica e o enchimento do enorme reservatório que inundou uma considerável área do município também contribuíram substancialmente para aumentar os impactos ambientais. Assim, a CESP - Centrais Elétricas do Estado de São Paulo, empresa responsável pela alteração do ecossistema na região, tem participado na elaboração de projetos, objetivando o reflorestamento, controle da erosão, desenvolvimento urbano, proteção e sustentação da fauna terrestre e aquática, assim como, a formação de áreas para recreação e lazer às margens do reservatório.

Considerando-se a situação atual, cada vez mais preocupante, devido aos variados processos de degradação ambiental causados a esta região tanto pelos impactos gerados pela formação do reservatório, quanto pelas atividades agrícolas realizadas de forma inadequada devido a falta de conscientização de alguns proprietários rurais surgiu a necessidade de ser avaliar as condições ambientais destas propriedades. Desta forma, realizou-se uma abordagem do ponto de vista social e econômico das propriedades, em que foram objetos de pesquisa a infraestrutura familiar, o nível tecnológico de produção e comercialização assim como as questões ambientais mais preocupantes do ponto de vista agropecuário.

Desde o ano de 2000 está em desenvolvimento na UNESP, Campus de Ilha Solteira, um projeto de diagnóstico socioambiental em propriedades agrícolas (pequenas, médias e grandes) no Estado de São Paulo, de modo a coletar dados sobre as diversas realidades do meio rural do Estado. Diversos trabalhos foram realizados no contexto de tal projeto, com a finalidade de avaliar as condições ambientais das propriedades rurais e a percepção ambiental de agricultores, entre os quais podem ser citados o de Arruda et al. (2001), no Assentamento Timboré em Castilho, SP, o de Poleto et al (2004), na Microbacia Hidrográfica do Córrego do Ipê em Ilha Solteira, SP, o de Américo et al. (2012) em Dobrada, SP e o de Carvalho et. al. (2012) em Santa Rita do Passa Quatro-SP e o de Prudente Jr. et. al em 2013 em Bauru - SP. 
Nesse sentido, o objetivo desse trabalho foi avaliar as condições sociais, econômicas e ambientais das propriedades rurais localizadas no bairro Cinturão Verde e nas grandes propriedades agrícolas no município de Ilha Solteira, Estado de São Paulo, Brasil. Essa avaliação teve como finalidade detectar possíveis problemas ambientais nessas propriedades e a partir de então sugerir futuros programas de educação ambiental que permitam a formação de agricultores conscientes e que possam contribuir efetivamente para a preservação dos recursos naturais dentro de um contexto de desenvolvimento sustentável.

\section{MATERIAL E MÉTODOS}

O município de Ilha Solteira - SP (Figura1) localiza-se na margem paulista do rio Paraná e abaixo da confluência com o rio São José dos Dourados (20³8'44', S 5106'35' 'W) a uma altitude de aproximadamente 335 metros. Para IPT, o município está situado na Província Geomorfológica do Planalto Ocidental, na região das "zonas indivisas". O clima da região em que se encontra Ilha Solteira é quente e úmido do tipo Aw, segundo a classificação de Koppen (CARDOSO, 1980). De acordo com dados da Estação Meteorológica da FEIS-UNESP, a temperatura média anual é de $24,1^{\circ} \mathrm{C}$ e a umidade relativa do ar média anual é de 70,8\% (HESPANHOL, 1996). A precipitação pluviométrica anual varia entre $1100 \mathrm{~mm}$ e $1300 \mathrm{~mm}$, com uma estação seca entre os meses de maio e setembro/outubro. A região é caracterizada por marcante contraste entre fortes chuvas de verão e fracas no inverno (LIMA, 1997). A vegetação é caracterizada pela Mata Tropical Latifoliada Semidecídua (formações de cerrado, cerradão e campos antrópicos).

O município está compreendido em uma área de 63.900 ha, com aproximadamente 25.000 habitantes. O município está localizado na região Noroeste do Estado de São Paulo, aproximadamente a $653 \mathrm{~km}$ de São Paulo, via rodovia Feliciano Sales da Cunha e via Anhanguera. Os municípios limítrofes de Ilha Solteira são os seguintes:

- Ao Norte, Rubinéia;

- Ao Sul, Itapura;

- Ao Oeste, Rio Paraná e Selvíria-M.S.;

- Ao Leste, Pereira Barreto.

Possui uma área agrícola de 46.254,30 ha com uma população na zona rural de 1.551 habitantes (IBGE, 2010). A área territorial rural do município, excluindo-se a área inundada pelo reservatório de Ilha Solteira, está distribuída da seguinte forma, conforme a Tabela 1.

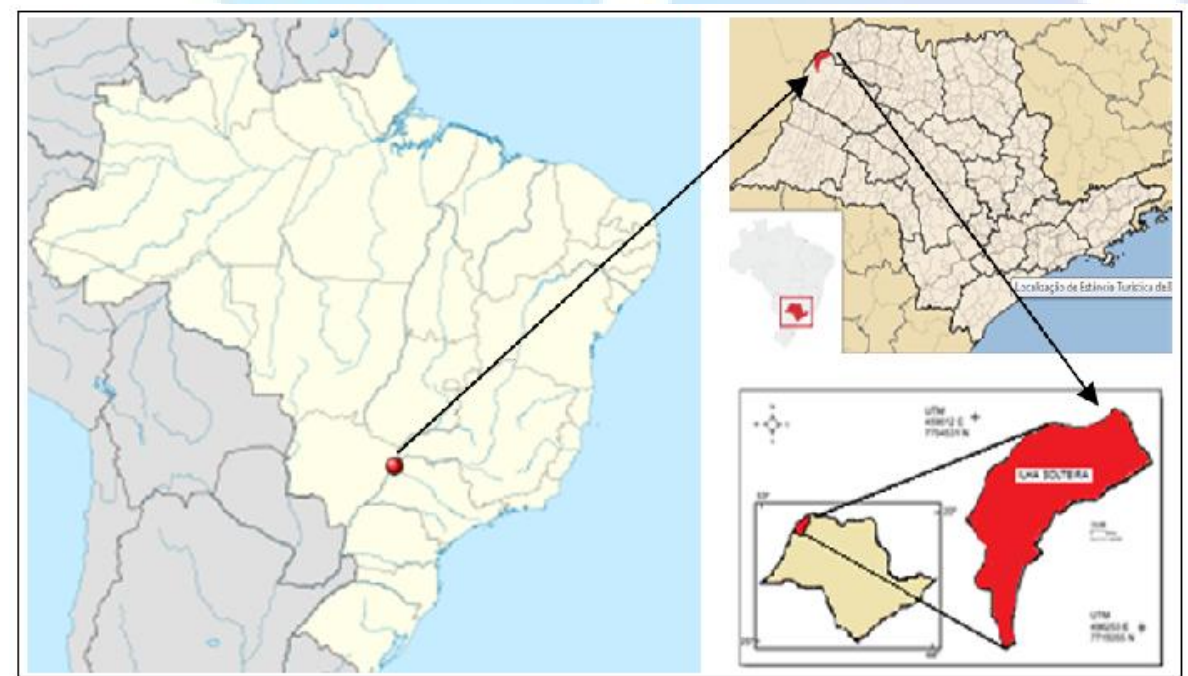

Figura 1. Localização do Município de Ilha Solteira no Estado de São Paulo e no Brasil. Fonte: Modificado de Wikipédia, a enciclopédia livre (2010). 
Tabela 1 - Uso atual da terra no município de Ilha Solteira - SP (LUPA, 2007/8).

\begin{tabular}{ccc}
\hline Exploração & Área ocupada (ha) & $\%$ \\
\hline Pastagem cultivada & $24.154,80$ & 52,22 \\
Culturas perenes & 568,40 & 1,23 \\
Culturas anuais & $17.929,50$ & 38,76 \\
Vegetação natural & $1.044,77$ & 2,26 \\
Área complementar & 426,00 & 0,92 \\
Área em descanso & 10,00 & 0,02 \\
Área com vegetação de & $2.099,60$ & 4,54 \\
brejo e várzea & 21,30 & 0,05 \\
Reflorestamento & $46.254,30$ & 100,00 \\
\hline Total & & \\
\hline
\end{tabular}

Observa-se que na época a maior área do município era ocupada por pastagem cultivada (24.154,80 ha), correspondendo a 52\%, vindo a seguir as culturas anuais representadas por produção de cana, milho, feijão, banana, sorgo e mandioca (17.959,50 ha) com 38,76\% do total. As áreas com vegetação natural representam 1.044,77 ha, o que corresponde a 2,26\% e as áreas com vegetação de brejo e várzea estão presentes em 2.099,60 ha correspondendo a 4,54\% das terras ocupadas, o que na totalidade representa apenas $6,8 \%$ de área ocupada com mata natural. As culturas perenes, representadas por produção de laranja, seringueira e eucalipto, por sua vez, estão presentes em 568,40 ha, o que corresponde a 1,23\% da área total.

Ressalta-se que com implantação de grande número usinas de produção de etanol na região, atualmente ganhou destaque, o cultivo de cana de açúcar que atualmente ocupa mais da metade das terras cultivadas. Em relação à exploração animal, predomina a bovinocultura de corte, com 32.284 cabeças, e a mista (corte e leite), com 9.568 cabeças, a avicultura de corte, com 2.008 cabeças/ano, a suinocultura, com 1036 cabeças, a equinocultura, com 565 cabeças, a caprinocultura com 383 cabeças e a ovinocultura com 255 cabeças (LUPA, 2007/8). O número, a área das propriedades agrícolas e o percentual de área ocupada no município de Ilha Solteira - SP está apresentado na Tabela 2.

Tabela 2 - Número, área das propriedades agrícolas e percentuais de área ocupada no município de Ilha Solteira - SP (LUPA, 2007/8).

Área Número de propriedades Percentual de área ocupada no município

$\begin{array}{ccc}\text { Até 50 ha } & 428(88,6 \%) & 9 \% \\ \mathbf{5 1} \text { a } 200 \text { ha } & 12(2,5 \%) & 3,1 \% \\ >\text { 200 ha } & 43(8,9 \%) & 87,9 \%\end{array}$


Verifica-se na Tabela 2 que 428 propriedades representando 88,6\% do total estão enquadradas como pequenas (até 50 ha), 12 propriedades (2,5\%) são de tamanho médio e 43 propriedades $(8,9 \%)$ são grandes propriedades. Apesar do número de propriedades pequenas ser de aproximadamente 10 vezes maior que as grandes propriedades, elas estão presentes em apenas 9\% das áreas ocupadas enquanto que aquelas representam $87,9 \%$ do total.

Para avaliar as condições sociais, econômicas e ambientais das propriedades rurais localizadas no município de Ilha Solteira - SP bem como a percepção ambiental de seus proprietários, foi aplicado um questionário com 26 questões, contendo quadros com alternativas para diversas de respostas. Foram observados os principais fatores que contribuem para a degradação ambiental, assim como, os padrões social e econômico dos proprietários, verificando a possível influência dos métodos conduzidos por suas práticas agrícolas, identificando as razões de abandono ou de cuidados relacionados à proteção e conservação do meio ambiente.

O questionário foi respondido por agricultores e pecuaristas, abrangendo um total de 50 propriedades rurais, correspondendo a uma área de 9.794 ha. $\mathrm{O}$ espaço amostral ficou dividido em 40 pequenas propriedades localizadas no projeto agrícola denominado Bairro Cinturão Verde, e 10 propriedades de grandes extensões, com suas áreas distribuídas nos limites do município de Ilha Solteira.

O questionário abordou as questões ambientais mais críticas da atualidade, entre elas, o problema da contaminação por uso de agrotóxicos; descarte de embalagens de defensivos agrícolas e destino final do lixo doméstico; poluentes e ações causadoras de assoreamento nos cursos de água; problemas relacionados à conservação do solo e as técnicas de controle; preservação de matas nativas e ciliares, e também, a percepção que o produtor rural tem em relação à importância da conservação e disponibilidade futura dos recursos naturais. A escolha das propriedades nessas distintas modalidades de produção ocorreu aleatoriamente e a quantidade de propriedades rurais pesquisadas satisfez a expectativa para a obtenção dos resultados.

A percepção dos impactos foi considerada dentro do conceito de que impacto ambiental é qualquer alteração das propriedades físicas, químicas e biológicas do meio ambiente, causada por qualquer forma de matéria ou energia resultante das atividades humanas que, direta ou indiretamente, afetam: a saúde, a segurança e o bem-estar da população; as atividades sociais e econômicas; a biota; as condições estéticas e sanitárias do meio ambiente; e a qualidade dos recursos ambientais (CONAMA, 1986).

\section{RESULTADOS E DISCUSSÃO}

De acordo com os dados obtidos nesse levantamento observou-se que a maioria da população do meio rural apresenta idade superior a 18 anos (64\%), com idade média de 35,3 anos. Em relação à composição familiar, verificou-se que 50\% das propriedades avaliadas apresentam composição familiar caracterizada por 1 a 3 indivíduos, $35 \%$ caracterizam-se por 4 a 5 e $15 \%$ possuem acima de 5 membros na família.

De modo geral, na maioria das propriedades a fonte de renda é obtida com a produção agrícola (80\%), enquanto que a minoria (20\%) recorre a atividades não agrícolas ou não possuem participação ativa no orçamento doméstico. Convém ressaltar que as propriedades no bairro Cinturão Verde são constituídas por pequenos lotes, geralmente menores que 10 ha, com média de 4,41 ha para as pesquisadas, em que a produção é feita predominantemente por meio de agricultura familiar, de forma diversificada, com predomínio das culturas de milho, laranja, limão, olericolas, pinha, mandioca, cana forragem, capim napier, café, manga, côco e pupunha.

As grandes propriedades apresentam área variando de 216 a 2.880 ha, com média de 962,4 ha e predomínio das culturas de milho, braquiária, cana, forragem capim napier, feijão, soja e cana 
de açúcar. Embora nessas propriedades a produção esteja voltada para a pecuária extensiva, e possua nível tecnológico de produção superior às pequenas propriedades, $50 \%$ apresentam problemas de conservação do solo e a comunidade que nelas reside possui condições culturais, sociais e econômicas semelhantes, e não possui participação nos rendimentos, pelo fato de serem somente moradores que trabalham na propriedade.

Quanto aos impactos causados ao meio ambiente pelas atividades agropecuárias, observouse que o descarte das embalagens de defensivos agrícolas nas propriedades é realizado a céu aberto $(5 \%)$, queimado $(10 \%)$ ou enterrado no solo (53\%), sendo que a maioria $(57 \%)$ faz devolução à revendedora. Isto demonstra a falta de conscientização de alguns proprietários rurais que fazem uso de agrotóxicos, contaminando a área e infringindo a legislação concernente a disposição final das embalagens, que exige o retorno à revendedora que recebe as embalagens vazias depois de realizada a tríplice lavagem, para posteriormente serem recicladas.

As respostas fornecidas por meio do questionário, observou-se que existem problemas relacionados com a aplicação dos agrotóxicos até descarte de suas embalagens vazias, constatandose casos de intoxicação de trabalhadores durante a manipulação e aplicação dos mesmos. Apesar das constantes recomendações quanto ao descarte seguro das embalagens, observa-se na prática, o seu abandono em locais de abastecimento dos pulverizadores, próximo aos mananciais de água, e reutilização para outros fins, como o acondicionamento de água e alimentos. Em cerca de $10 \%$ das propriedades agrícolas, o descarte é realizado por meio da queima de embalagens no próprio local de uso, sem terem consciência que este descarte constitui fonte altamente poluidora do meio ambiente, podendo contaminar o solo, fontes de água, e intoxicar pessoas e animais na propriedade.

Os resultados obtidos neste estudo diferenciam-se dos verificados por Américo et al. (2012), no qual a maioria $(96,7 \%)$ do produtores rurais do município de Dobrada-SP realizam a devolução adequada das embalagens, indicando que estes indivíduos possuem consciência dos danos causados por agrotóxicos à saúde humana e ao ambiente e da importância da devolução deste tipo de embalagem.

A política pública de cada município também é um fator que reflete nas atitudes corretas de descarte de cada indivíduo, o que indica que a prefeitura de Ilha Solteira precisa de um programa melhor de descarte correto das embalagens vazias bem como dos resíduos sólidos gerados nas propriedades.

Foi observado também que $20 \%$ das grandes propriedades e $27,5 \%$ das pequenas não utilizam EPI's (equipamentos de proteção individual), o que gera intoxicações com riscos de morte aos trabalhadores, valores mais baixos que os encontrados por Tosti (2014), no município de Santa Fé do Sul e região onde $60 \%$ das propriedades fazem uso de EPIs, mesmo que não seja o conjunto completo, enquanto que $40 \%$ das propriedades não utilizam nenhum tipo de equipamento, gerando assim maior susceptibilidade a casos de contaminação.

O destino do resíduo sólido doméstico na maioria das propriedades agrícolas apresenta inadequações quanto a sua eliminação, excetuando algumas pequenas propriedades do bairro Cinturão Verde, que por ficarem próximas à zona urbana são favorecidas com a coleta de lixo do serviço municipal. Os lotes mais afastados, entretanto, juntamente com as grandes propriedades, não são beneficiados, e por isso queimam ou enterram o lixo doméstico, seja orgânico ou inorgânico, no próprio local de origem. O lixo é coletado em $40 \%$ das propriedades, enterrado em $35 \%$, queimado em $25 \%$, não sendo encontrado em céu aberto.

Quanto ao descarte de resíduo sólido doméstico nas grandes propriedades, 100\% queimam, enterram ou deixam à céu aberto. Esses resultados diferem dos encontrados por Prudente Junior et al. (2013) em um levantamento com 30 propriedades na região de Bauru - SP, nas quais 16,67\% dos produtores queimam seus resíduos e uma parcela de $2,67 \%$ os enterram.

O estado atual do solo nas propriedades agrícolas do bairro Cinturão Verde, embora constituído por pequenos lotes, deixa a desejar, pois $47,5 \%$ das propriedades apresenta-se com 
problemas de erosão em sulcos, que resultam em problemas de assoreamento em $38 \%$ delas. O problema é um pouco maior nas grandes propriedades, onde $60 \%$ apresentam problemas de erosão em sulcos, $5 \%$ problemas de assoreamento e $5 \%$ problemas com voçorocas. Nas pequenas propriedades, os problemas podem estar mais relacionados à falta de técnicas de contenção das erosões, devido ao pequeno poder aquisitivo dos proprietários, que em alguns casos têm dificuldades até mesmo para se manter nos lotes. Nas grandes propriedades, o problema pode estar mais relacionado à pecuária extensiva onde o pisoteio do gado contribui muito para os processos erosivos.

Com base nas respostas dos questionários, os proprietários rurais demonstraram ter consciência de que dependem do uso e da exploração do solo para sua sobrevivência, reconhecem a necessidade de técnicas e métodos mais eficientes para sua conservação, porém nem todos conseguem evitar os problemas de degradação, embora seja de conhecimento comum a maioria deles que o manejo inadequado do solo ocasiona erosão, voçorocas, e assoreamento de córregos, rios e lagos, além desses fatores contribuírem para a diminuição da fertilidade, da produção e da produtividade.

Faz-se necessário a adoção por parte desses produtores de técnicas de manejo e de técnicos qualificados, a fim de auxiliá-los na utilização do solo, de maneira racional, preservando suas características e condições, favorecendo o meio ambiente e gerando retorno satisfatório do ponto de vista econômico.

No que se refere às fontes de utilização de água, a disponibilidade e boa qualidade são condições fundamentais para a produção agrícola e para o ecossistema regional. Esta disponibilidade da água pode ser o fator determinante para a viabilidade do sistema de produção.

Nos pequenos lotes do bairro Cinturão Verde, a água para consumo é tratada em $90 \%$ das propriedades agrícolas. $\mathrm{Na}$ área de abrangência da pesquisa existe grande quantidade de nascentes e pequenos córregos, e também, poços cacimbas com retirada manual ou por bombeamento, para fins domésticos ou agrícolas. Nas grandes propriedades rurais, apesar da utilização das fontes a partir dos corpos de água existentes como rios, córregos, açudes e represas, para o consumo animal, o suprimento de água para consumo humano dá-se predominantemente por captação em poços cacimba e semi-artesianos (Tabela 3). A região do município de Ilha Solteira é amplamente privilegiada em rios e represamentos de água, sendo conhecida como "região dos grandes lagos".

Tabela 3 - Fontes de água, em porcentagem, nas propriedades rurais do bairro Cinturão Verde e nas grandes propriedades do município de Ilha Solteira - SP.

\begin{tabular}{ccc}
\hline Fontes de água & Cinturão Verde (\%) & Grandes Propriedades (\%) \\
\hline Rios & 5 & 10 \\
Córregos & 10 & 60 \\
Nascentes & 5 & 50 \\
Represas & 5 & 60 \\
Poços & 30 & 100 \\
Água tratada & 90 & 2 \\
\hline
\end{tabular}

De acordo com este estudo, $30 \%$ das propriedades lançam seus esgotos em fossas sépticas enquanto que $4 \%$ conta com rede de esgotos, por estarem próximas do meio urbano, e a maioria, $66 \%$, utiliza fossas negras, o que pode comprometer seriamente a qualidade da água do lençol freático em caso de contaminação. De acordo com Tosti (2014), 86\% das propriedades analisadas em Santa Fé do Sul e região lançam seu esgoto em fossas negras, e o restante (14\%) faz uso da 
fossa séptica para lançamento do esgoto produzido no local. O elevado uso de fossas negras pode ser um fator a ser observado com certa cautela, pois tais fossas não são revestidas internamente, além de não possuírem estágios adicionais, assim como os existentes nas fossas sépticas, por onde o esgoto passa, diminuindo seu potencial de infiltração no solo e consequentemente reduzindo o risco de contaminação dos lençóis freáticos, perda na qualidade da água, prejuízo ao ambiente e ao ser humano.

\section{CONCLUSÕES}

Embora se tenham evidenciado respostas favoráveis à conservação do meio ambiente, observou-se certa deficiência na realização do mesmo, uma vez que certas ações são tomadas trazendo impactos negativos, tanto do bairro Cinturão Verde quanto das grandes propriedades. Estes impactos são traduzidos pelos problemas de erosão, principalmente nas grandes propriedades, formas inadequadas de disposição dos resíduos sólidos, inadequação no descarte de embalagens de agrotóxicos, pela falta de EPI’s em algumas propriedades e pelo lançamento de grande parte dos esgotos em fossas negras.

Com o objetivo de motivar esses proprietários rurais à adoção de práticas agrícolas preventivas e conservadoras, assim como, realizarem um trabalho eficaz e concreto, deve ser implantado um programa de educação ambiental nessas comunidades rurais, a fim de contribuir para a formação de pessoas conscientes, com visão crítica quanto aos problemas ambientais, tornando-os capazes de identificarem e inibirem os agentes promotores de impacto ambiental, mantendo uma conduta satisfatória em relação ao equilíbrio natural do meio que vivem.

\section{REFERÊNCIAS}

AMÉRICO, J.H.P.; CARVALHO, S.L.; GONZAGA, M. L; FREITAS LIMA, E.A.C.;ARAÚJO, C.A.M. Condições ambientais de propriedades agrícolas e percepção ambiental de produtores rurais da região de Dobrada - São Paulo, Brasil. Holos Environment, Rio Claro, v.12, n 2, p. 241-249, 2012.

ARRUDA, S.A.; CARVALHO, S.L.; FREITAS LIMA, E.A.C. ARAÚJO, C.A.M. Percepção ambiental de produtores rurais e das condições ambientais de seus lotes agrícolas no Assentamento Timboré em Castilho-SP. In: Encontro Sobre Educação Ambiental na Agricultura, 3, Campinas, Anais... p. 22, 2001.

CARVALHO, S.L.; ALMEIDA, F.; FREITAS LIMA, E.A.C. Avaliação das condições sócioeconômico-ambientais de algumas propriedades Agrícolas no Município de Santa Rita do Passa Quatro - SP. Fórum Ambiental da Alta Paulista, Tupã v.8, n.2, p.348-359, 2012.

CONAMA - Conselho Nacional do Meio Ambiente. Disponível em: <http://www.planetaorganico.com.br > Acessado em 28/Dez/2004. Ambiente, IBAMA. Resolução CONAMA 001, de 23/Jan/1986. Publicado no D.O.U de 17 /2/86.

IBGE - Instituto Brasileiro de Geografia e Estatística. Censo, 2000.

INPE - LAND SAT TM 5. São José dos Campos: Instituto Nacional de Pesquisas Espaciais, 19871988. Imagem de satélite. Canais 3,4 e composição colorida 3, 4 e 5. Escala 1:100.000. 
MOURA, L.A.A. Qualidade e Gestão Ambiental, 4. ed. São Paulo, Juarez de Oliveira, 2004, p.27-45.

PENDER, J.; NKONYA, E.; JAGGER, P.; DICK, S. e SALI, H. Strategies to increase agricultural productivity and reduce land degradation: evidence from Uganda, Agricultural economics, Malden MA 02148, USA, v. 31, p. 181-195, 2004.

POLETO, C; CARVALHO, S.L. Problemas de degradação ambiental em uma microbacia hidrográfica situada no município de Ilha Solteira - SP, Brasil e sua percepção pelos proprietários rurais. Holos Environment, Rio Claro, v.4, n.1, p.68-80, 2004.

PRUDENTE JUNIOR, A.C.; CARVALHO, S.L.; FREITAS LIMA, E.A.C. Percepção ambiental de produtores rurais e condições ambientais de algumas propriedades agrícolas da região de Bauru SP (dados parciais), Fórum Ambiental da Alta Paulista, Tupã, v.9, n.6, p.105-116, 2013.

SÃO PAULO (Estado). Secretaria de Agricultura e Abastecimento. Coordenadoria de Assistência Técnica Integral. Instituto de Economia Agrícola. Levantamento censitário de unidades de produção agrícola do Estado de São Paulo - LUPA 2007/2008. São Paulo: SAA/CATI/IEA, 2008.

TOSTI, R.S; CARVALHO, S.L; FREITAS LIMA, E.A.C. Condições ambientais de algumas propriedades agrícolas de Santa Fé do Sul - SP e região. Fórum Ambiental da Alta Paulista, Tupã, v.10, n.12, p.184-196, 2014. 